\title{
A CONTRIBUIÇÃO DOS PROJETOS DE EXTENSÃO PARA A FORMAÇÃO INICIAL DE DOCENTES ${ }^{1}$
}

\author{
Edina Regina Baumer ${ }^{2}$ \\ Jaline Nunes Eufrasio ${ }^{3}$ \\ Sheila de Souza Brigido ${ }^{4}$
}

A cada ano vem aumentando a preocupação acerca da educação, de um modo geral e sobre a formação de professores para a educação básica; se pensa muito sobre a relação entre teoria e prática que acaba por caracterizar as tendências pedagógicas na escola, em diferentes tempos e espaços geográficos. Com esse avanço, mesmo que em passos lentos, vemos uma mudança significativa nos modos de ensinar e aprender o que nos faz questionar se nossa formação enquanto acadêmicos de licenciatura em Artes Visuais consegue dar conta da demanda, se realmente estamos nos preparando para nos tornarmos professores responsáveis e comprometidos com o ensino e aprendizado dos nossos alunos, no campo do conhecimento em arte.

Professor e aluno necessitam de formação contínua e aprendizagem permanente, em que o aprender a aprender, seja para ensinar, seja para seguir aprendendo arte ao longo da vida, é princípio para enfrentar um mundo repleto de mudanças, conhecimentos novos e incertezas nos horizontes, econômico, político, profissional, social e filosófico. (ARSLAN, 2011, p.6).

É pensando nessa formação contínua que surgem, ao longo dos anos, vários projetos de extensão, que visam uma aproximação entre as teorias e as práticas pedagógicas, que oportunizam aos acadêmicos, mesmo antes da conclusão da graduação, uma formação com maior qualidade. Na UNESC, as políticas de extensão partem do princípio que:

Nas atividades extensionistas a universidade dialoga com a comunidade. Ao comunicar-se com a realidade local, regional ou nacional, coletando dados e informações e realizando estudos, tem a possibilidade de aprender com ela

\footnotetext{
${ }^{1}$ Esse artigo foi apresentado no PIBID/SUL - PARFOR/SUL - ENLICSUL - 1 SEMINÁRIO REGIONAL PROESDE/LICENCIATURAS/SC, com o número de identificação 23411.

2 Edina Regina Baumer (UNESC) - e-mail: edinabaumer@gmail.com

3 Jaline Nunes Eufrasio (UNESC) - e-mail: jalieufrasio@r7.com

${ }^{4}$ Sheila de Souza Brigido (UNESC) - e-mail: sheilinha_souza@live.com
} 
e constantemente rever sua própria estrutura, seus currículos e suas ações. (UNESC, 2008, p. 2).

Esses projetos alcançam seus objetivos, possibilitando aos estudantes conhecerem os espaços de educação - as escolas - e também trocarem conhecimento com professores já em atuação. Dessa forma, ao mesmo tempo se consegue uma formação continuada para professores já graduados, que estão atuando na medida em que estes podem rever suas ações de ensino e retomarem os estudos para se aperfeiçoarem. Os alunos da educação básica também se beneficiam, pois nesse contato se sentem mais próximos da universidade e da possibilidade de ingressar nela no futuro; eles veem a movimentação na escola, com a presença de estudantes universitários e se sentem valorizados, passando a reconhecer ainda mais o processo de ensino e aprendizagem nas diversas áreas do conhecimento.

Em especial, neste artigo, tratamos do conhecimento na área da arte, ressaltando que, segundo a LDB n. 9.394/96 "§ $2^{\circ}$ O ensino da arte, especialmente em suas expressões regionais, constituirá componente curricular obrigatório nos diversos níveis da educação básica, de forma a promover o desenvolvimento cultural dos alunos.". (BRASIL, 1996).

Os projetos dos quais estamos fazendo parte são 'O Museu na Escola' e o Programa Institucional de Bolsa de Iniciação a Docência (PIBID) - subprojeto de Artes Visuais. Ambos contribuem na nossa formação acadêmica e profissional e embora sejam projetos que apresentam propostas diferentes de atuação, sua finalidade é pensar educação de qualidade e promover conhecimento.

O projeto Museu na Escola é uma extensão do Museu da Infância que é uma instituição pertencente à Universidade do Extremo Sul Catarinense - UNESC, um espaço que, desde 2005 preserva, promove e divulga objetos/atividades feitos para crianças (como brinquedos, livros e jogos) a produção das crianças (seus desenhos, pinturas e brinquedos) e também o que é produzido sobre a infância (como filmes e livros).

É um Núcleo Itinerante, como uma continuidade da proposta do Museu, que pretende sensibilizar as pessoas e incluir um público maior, inserindo aqueles que ainda não se veem contemplados no Museu da Infância ou que não valorizam a cultura de visitar os Museus. Esse projeto de extensão universitária acontece nas 
escolas da rede municipal de Criciúma envolvendo crianças das séries iniciais do ensino fundamental e sua função é ampliar o repertório cultural dos alunos no intuito de promover uma aproximação entre o Museu, as crianças, a escola e a Universidade, mostrando que o Museu é uma instituição de portas abertas e ao alcance da comunidade da região.

\begin{abstract}
Os diversos meninos e meninas que hoje percorrem os inúmeros museus e centros culturais espalhados pelo país - aqui faço um recorte mais específico nos de arte - vão cada vez mais encontrando, diante de seus olhos, obras de todos os portes, épocas, estilos, técnicas, linguagens e suportes. Obras de valor variado, às vezes de qualidade duvidosa, obras que fazem rir, chorar, indagar; obras que não tocam, não causam incômodo ou estranheza. As imagens paradas (fotografias, pinturas) exigem, do contemplador, o movimento. Elas revivem a cada olhar, no ritmo determinado por aquele que olha; sua duração é aquela da possibilidade de observação. Diferentemente, as artes em movimento determinam, elas próprias, seu tempo. (LEITE, 2006, p. 78).
\end{abstract}

A dinâmica do projeto de extensão 'O Museu na escola' se divide em quatros encontros, no período de um mês em cada escola. No primeiro encontro conversamos com a direção, apresentamos o projeto, qual seu propósito e definimos as turmas que irão participar e qual tema iremos abordar, já que uma das possibilidades é relacionar a atuação do projeto com outros projetos que estejam acontecendo na escola, naquele período. No segundo encontro conhecemos as turmas, apresentamos o museu através de uma brincadeira 'Boliche do Museu', levantamos questões sobre o que é um museu, para que serve um museu, o que é um acervo, e assim através de um diálogo/brincadeira identificamos o que os alunos têm de conhecimento sobre o museu, possibilitando os alunos saberem da existência do Museu da Infância e divulgando a importância do mesmo.

Essas reflexões nos levam a pensar mais intensamente sobre o lúdico, sobre o jogo e o brincar como elementos fundamentais no cotidiano infantil. A arte nas séries iniciais e no contexto da educação infantil não pode estar desvinculada desses elementos, uma vez que a sua própria natureza comporta o ato básico e humano de todos nós - a imaginação. (PILLOTTO, 2008, p. 43).

No terceiro encontro levamos a vitrine expositora, com objetos do acervo do museu, relacionados com o tema específico determinado no encontro com a direção da escola. Como o Museu da Infância já existe há dez anos na universidade, acervos de diferentes tempos, espaços, e culturas compõem o seu acervo e para selecionarmos o que levaremos para a escola necessitamos de uma constante 
pesquisa a fim de conhecer as histórias, a significação de cada objeto, ampliando o nosso repertório cultural também, fazendo uma aproximação com outros povos, culturas, aprendendo a preservar memórias. Vale ressaltar que:

Aquilo que chega aciona acervos e, num processo de familiarização de códigos não pré-convencionados, possibilita a interpretação. Portanto, entendendo o acervo imagético do sujeito como toda a memória do que foi visto/ouvido/ sentido por ele, percebe-se que é esta memória que possibilita a incorporação de novas imagens. (LEITE, 2006, p. 79).

A vitrine expositora fica durante uma semana na escola, após o encontro de mediação cultural que realizamos com as turmas escolhidas pela direção. Essa permanência prolongada permite que os alunos que tiveram a mediação possam apresentar e divulgar o museu para os seus colegas, professores e comunidade em geral, falando sobre um pouco do Museu da Infância, dos acervos expostos, suas histórias e sua importância.

Neste artigo trazemos o relato da experiência onde a vitrine expositora que foi para a escola expôs objetos como bonecas negras gêmeas, Abayomis, Saci Pererê, arco e flecha, cestos indígenas, integrando-se ao projeto interdisciplinar que já estava acontecendo na escola, com a temática da cultura afro-brasileira e indígena. Durante os dois anos de atuação do projeto 'O Museu na escola', uma boa parte das escolas envolvidas solicitou a mediação cultural sobre esse assunto o que nos fez perceber a preocupação com a diversidade cultural, seguindo a orientação da LDB n. 9.394/96, que em seu artigo 26-A, determina que:

Art. 26-A. Nos estabelecimentos de ensino fundamental e de ensino médio, públicos e privados, torna-se obrigatório o estudo da história e cultura afrobrasileira e indígena. $\S 1^{\circ} \mathrm{O}$ conteúdo programático a que se refere este artigo incluirá diversos aspectos da história e da cultura que caracterizam a formação da população brasileira, a partir desses dois grupos étnicos, tais como o estudo da história da África e dos africanos, a luta dos negros e dos povos indígenas no Brasil, a cultura negra e indígena brasileira e o negro e o índio na formação da sociedade nacional, resgatando as suas contribuições nas áreas social, econômica e política, pertinentes à história do Brasil. $\S 2^{\circ}$ Os conteúdos referentes à história e cultura afro-brasileira e dos povos indígenas brasileiros serão ministrados no âmbito de todo o currículo escolar, em especial nas áreas de educação artística e de literatura e história brasileiras. (BRASIL, 1996).

Dessa forma, o projeto contribuiu muito com a formação das acadêmicas extensionistas visto que certificou para as estudantes, o esforço das instituições escolares em aderir e cumprir as determinações legais para a educação no país. 
No quarto encontro, depois que as crianças conheceram um pouco sobre o Museu da Infância e tiveram seu repertório cultural ampliado no próprio espaço da escola, elas vão para a universidade conhecer os demais núcleos do museu e o ambiente da universidade. Nessa visita, as crianças participam de uma oficina artística que torna-se um momento onde os alunos aprendem infinitas possibilidades de criação e como eles são os criadores, vemos que dão mais significado à sua produção. Nessa proposta, outras duas bolsistas de ação educativa do Museu da Infância também atuam, enriquecendo a vivência, ampliando as redes de contato e de carinho com que o projeto é desenvolvido junto às professoras e às crianças. É uma forma também de oportunizar o desenvolvimento da autonomia, pois criar um objeto é dar sentido a algo que antes não existia ou ressignificar algo que já existia.

\begin{abstract}
A aprendizagem artística deixará no aluno marcas positivas, um sentimento de competência para criar, interpretar objetos artísticos e refletir sobre arte, situar as produções, aprender a lidar com situações novas e incorporar competências e habilidades para expor publicamente suas produções e ideias com autonomia. (ARSLAN, 2011, p. 9).
\end{abstract}

Essa experiência de criação acaba proporcionando aos alunos o desenvolvimento de competências e habilidade que servirão para a sua formação e mesmo o museu não sendo específico de artes, percebemos a relação entre conhecimentos: nenhum conhecimento é isolado e todas as áreas de conhecimento, de alguma forma acabam se completando. O Museu da Infância, o projeto 'O Museu na escola' e a arte, de alguma forma falam de cultura, trazem histórias, pensam educação confirmando a ideia de que "como espaços onde se aprende com a cultura e não somente sobre a cultura, os museus possibilitam que os sujeitos vejam o mundo a sua volta e vejam-se no mundo, em seus diferentes papéis e identidades multifacetadas.". (LEITE, 2012, p. 346).

Embora o projeto permaneça apenas por um mês em cada escola, ainda assim conseguimos estabelecer uma relação de confiança e respeito com a comunidade escolar, causando admiração pela instituição museu reportando todos os envolvidos ao conceito de que os museus "são, sobretudo, espaços de significação, lugares de experiência formativa que transita na interface da cognição com o sensível.". (LEITE, 2012, p. 348). Às crianças são apresentadas a coisas que jamais viram, ou se viram não souberam o que era e que através da mediação tiveram outro tipo de olhar para aquele objeto 'acervo', aquela história, aquela memória de infância. 
O outro projeto no qual fazemos parte - e que trazemos para este artigo é o Programa Institucional de Bolsa de Iniciação a Docência (PIBID) - subprojeto de Artes Visuais - que atende escolas da rede municipal e estadual da cidade de Criciúma - SC. Participando dele acerca de quase dois anos, atuamos em três escolas, tivemos a orientação de três professores supervisores e nos deparamos com realidades sociais bem dispares uma das outras. Esse fato, por si só, já contribuiu muito com a nossa formação de licenciados, professores para a educação básica.

No começo do projeto nos reuníamos na Universidade do Extremo Sul Catarinense, com todos os integrantes da proposta: bolsistas, professores supervisores (da escola) e professores coordenadores de área, que são professores da universidade. Esses encontros colocam como intuito o pensar a educação de um modo geral, refletir sobre a formação contínua, sobre a nossa preparação como professores e foram e ainda são muito significativos. A frequência das reuniões é de uma vez por semana na Universidade sempre com leituras sobre arte e a formação do professor, troca de experiências e o exercício da escrita. Depois vamos à escola, também uma vez por semana, quando conhecemos a turma que vamos acompanhar ao longo do ano letivo e passamos a observar a professora de Artes em atuação. Nesses encontros procuramos perceber como os alunos recebem o que a professora propõe, bem como sua interação nos momentos de atuação dos bolsistas, trazendo proposições que intencionam a contribuição de todo o processo de ensino e aprendizagem - não só dos alunos da educação básica, mas nosso processo também. Assim vamos aprendendo com eles, percebendo suas necessidades de conhecimento e a nossa necessidade de promover estratégias em que seja possível ensinar e aprender. Sobre isso, Baumer e Honorato (2010, p. 2) apontam que:

A formação continuada é uma proposta que caminha na direção da qualidade do ensino e está prevista na LDB n. 9.394/96, no artigo 43, que trata das finalidades da educação superior. No inciso II, a lei coloca como finalidade "formar diplomados nas diferentes áreas de conhecimentos [...] e colaborar na sua formação contínua" ao que acrescentamos: "promover a divulgação de conhecimentos culturais, científicos e técnicos que constituem patrimônio da humanidade" (LDB 9.394/96, art. 43, inciso IV). Ao tratar dos profissionais da educação, o artigo 61 apresenta seus fundamentos, entre eles "a associação entre teorias e práticas, inclusive mediante a capacitação em serviço” (LDB 9.394/96, art. 61, inciso I) e no artigo 63, a determinação sobre a necessidade de "programas de educação continuada para os profissionais de educação dos diversos níveis" (LDB 
9.394/96, art. 63, inciso III) que segundo Carneiro (2007, p. 168) "destinamse à atualização profissional de docentes".

Com os professores aprendemos de que forma devemos agir em sala de aula, como planejar as aulas, qual é a metodologia mais eficaz no ensino, como saber o que é fundamental para a formação dos alunos, quais os conteúdos para aquela determinada faixa etária, qual a importância daquele conhecimento para os alunos e quais objetivos pretendemos alcançar.

Entre tantas observações, percebemos que é muito comum dentro das escolas as discussões sobre a cultura Africana e Indígena, embora esses temas fiquem muito restritos a datas comemorativas como o Dia da consciência negra e o Dia do índio. Nessas ocasiões o que vemos é a confecção de lembranças, de murais decorativos e a ausência de propostas para atribuição de sentido e significação das culturas; atividades que não trazem de fato a importância desses temas para a formação de cada um, propondo ações de mera reprodução para marcar uma data e - que constatamos são as crianças fazendo porque alguém disse que era importante.

É necessário pensarmos outra forma de trazer esses temas para a reflexão nas escolas e assim fortalecer a identidade histórico-cultural presente em nossa sociedade, porque só assim iremos romper os preconceitos existentes e garantir uma educação de igualdade para todos, reconhecendo e valorizando outras culturas, segundo a proposta Curricular de Santa Catarina:

[...] determinada pelas Leis $\mathrm{n}^{\circ}$ 10.639/2003 e $\mathrm{n}$ - 11.645/2008 (BRASIL, 2003b, 2008b), que torna obrigatório o ensino de conteúdos de matriz afrobrasileira, africana e indígena nos currículos das escolas. Advinda das políticas de reparação, objetiva atender as demandas das populações negra e indígena brasileira no sentido de vislumbrar ações de reconhecimento e de valorização de sua identidade histórico-cultural na educação. (SANTA CATARINA, 2014. p.66.)

Foi pensando nessa regulamentação e na própria LDB n. 9.394/96 já citada anteriormente neste artigo, que reafirmamos a importância de se trabalhar esses temas na escola e possibilitar maior compreensão para os alunos.

O relato que trazemos para este artigo refere-se à atuação dos bolsistas do PIBID em conjunto com a professora supervisora que já trazia o tema cultura afro para a suas aulas. $\mathrm{Na}$ ocasião fizemos um planejamento a partir do que pesquisamos sobre artistas afro-brasileiros. No começo foi difícil, pois quando 
encontrávamos algum, não havia muito material de pesquisa, então após persistirmos no estudo, conhecemos um pintor chamado Wilson Tibério. A professora supervisora estava desenvolvendo um projeto de brinquedos e brincadeiras antigas por sentir a necessidade de seus alunos, de brincarem uns com os outros já que vivemos num mundo tão tecnológico em que é muito comum ficarmos em nossos computadores, celulares, tabletes, e videogames e que as relações interpessoais acabam se perdendo.

Optamos por juntar os dois temas: brinquedos e brincadeiras antigas e as artes africanas. Primeiramente apresentamos o artista e sua trajetória no mundo das artes e depois os desafiamos para o 'jogo dos sete erros', com quadros do artista, uma forma lúdica para falar sobre a arte afro-brasileira.

Depois propusemos criar objetos sonoros, para brincar de amarelinha africana - uma amarelinha diferente da que conhecemos habitualmente - onde não existe pedra e dá para jogar quatro pessoas ao mesmo tempo. É uma brincadeira que propõe a cada um, dançar no ritmo da música sem encostar o pé na linha. Enquanto quatro alunos jogavam na amarelinha africana, os demais produziam os sons com os objetos que eles criaram e que havíamos ensaiado na sala em outro momento, então esses davam o ritmo da dança para os alunos que estavam posicionados nas linhas da amarelinha. Foi uma ótima experiência, pois fizemos relações entre as linguagens, não foram proposições isoladas, elas estavam ali juntas, na qual trabalhamos música, dança e as artes visuais. Além dessa proposição depois tivemos os brinquedos e brincadeira antigas, como bilboquê, pula corda, varetas, dominó, entre outras.

Essa proposta foi desenvolvida em uma das escolas contempladas com o PIBID; em outra escola partimos para a produção do grafite nos muros da escola a partir dos estudos sobre a gravura em um festival sobre a cultura africana, com apresentações, produções desde vestimentas, cenário, música, dança. Algumas pibidianas apresentaram uma dança afro, então a partir dessas duas experiências vemos que de alguma forma se está pensando cultura no ensino da arte, tem se buscado trazer esses conhecimentos para as escolas, para os alunos: "[...] o desenvolvimento cultural, entendido como o conhecimento, a compreensão e a aceitação da diversidade das culturas e promove o reconhecimento de si mesmo enquanto sujeito da cultura, produtor ou apreciador dos objetos artísticos.". (BAUMER; HONORATO, 2010, p. 11). 
Mas ainda assim falta muito e embora os alunos tenham tido uma experiência, faltava o contato com os objetos de outras culturas; vendo essa necessidade, uma das professoras supervisoras pediu para o projeto de extensão ' $O$ Museu na escola' realizar sua atuação naquela escola, oportunizando aos alunos um maior aprofundamento no assunto, é nesse momento que os projetos se encontram e fazem parceria, porque ambos pensam em ampliar o repertório cultural, ambos contribuem para a formação dos alunos e nossa também.

Com a vitrine expositora com mais objetos do acervo, pertencentes à cultura africana, e toda contextualização feita pelos bolsistas, os alunos estão dando mais sentido as suas produções sobre o tema nas aulas de artes, porque eles conseguiram compreender de fato a importância da cultura africana na formação deles, porque faz parte da nossa construção de identidade. Além dos alunos fazerem esse reconhecimento da cultura africana, nós bolsistas acabamos aprendendo também, porque estamos em constante contato com o acervo de objetos africanos, sendo assim todos nós nos tornamos mais próximas dessa cultura tão diversificada.

Podemos afirmar que os projetos veem contribuindo para a nossa formação tanto acadêmica quanto profissional, pois ambos nos levam a pesquisar, estudar mais, a rever nossas práticas; acabamos nos moldando ao longo do processo e passamos a acreditar que estamos em constante mudança. Estar na escola, seja por um ano em uma única escola, ou uma semana em cada uma, nos permite conhecer realidades diversas, pessoas diferentes com objetivos e ideias singulares. Ver como se organizam as escolas, como funcionam, é importante porque em breve será nosso espaço diário enquanto professoras de artes, logo esse contato antecipado nos permite ter mais confiança e preparação para enfrentar os desafios que nos esperam na profissão docente.

Não basta aprender, é necessário vivenciar, experimentar e atuando como bolsistas de extensão, aprendemos diariamente com professores da educação básica e da universidade, com alunos, com gestores e com a comunidade escolar.

Pensar educação é também pensar na formação do professor. 0 professor não é o possuidor de conhecimentos, pois esses se encontram em toda parte, os alunos podem acessar na internet, nos livros, mas o professor é aquele que organiza as estratégias do processo de ensino e aprendizagem; ele direciona os alunos onde procurar, para que procurar e porque procurar, e a partir da mediação 
do professor os alunos refletem sobre o assunto e se posicionam de forma crítica sobre os temas, sobre as proposições.

\section{REFERÊNCIAS}

ARSLAN, Luciana Mourão. O ensino de Arte no inicio do século XXI. São Paulo: Cengage Learning, 2011. P. 1-13.

BAUMER, Édina R.; HONORATO, Aurélia R. de S. Educação estética: uma proposta de formação continuada para professores de arte. Disponível: <http://www.portalanpedsul.com.br/admin/uploads/2010/Educacao_e_Arte/>

BRASIL. Lei de Diretrizes e Bases da Educação Nacional. Lei n. 9.394, de 20 de dezembro de 1996.

LEITE, Maria Isabel. Crianças, velhos e museu: memória e descoberta. Cad. Cedes, Campinas, vol. 26, n. 68, p. 74-85, jan./abr. 2006. Disponível em:

$<$ http://www.cedes.unicamp.br>

LEITE, Maria Isabel. Museu: espaço impulsionador de reconfigurações identitárias docentes. Cad. Cedes, Campinas, vol. 32, n. 88, p. 335-350, set.-dez. 2012. Disponível em:< http://www.cedes.unicamp.br>

PILLOTTO, Sílvia S. D. A arte e seu ensino na contemporaneidade. In: MACOWIECKY, Sandra; OLIVEIRA, Sandra R. e (orgs). Ensaios em torno da arte. Chapecó: Argos, 2008. p. 35- 53.

SANTA CATARINA. Proposta Curricular de Santa Catarina: formação integral na educação básica. Secretaria de Estado de Educação, 2014.

UNIVERSIDADE DO EXTREMO SUL CATARINENSE. Resolução n06/2008/CONSU. Políticas de Extensão da UNESC. Criciúma, 2008. 